\title{
Challenges and solutions for autism in academic geosciences
}

\author{
Nicola C. Taylor and Jessica H. Johnson \\ School of Environmental Sciences, University of East Anglia, Norwich, UK \\ Correspondence: Nicola C. Taylor (nicola.c.taylor@uea.ac.uk)
}

Received: 26 November 2019 - Revised: 30 March 2020 - Accepted: 7 April 2020 - Published: 23 April 2020

\begin{abstract}
Researcher diversity promotes research excellence. But academia is widely perceived as inaccessible to those who work in non-stereotypical ways, and disabled researchers are consequently chronically under-represented within higher education. The barriers that academia presents to the inclusion and success of disabled individuals must therefore be understood and removed in order to enhance researcher diversity and improve the quality and quantity of research. Autism is a disability that is particularly underrepresented within higher education, despite many autistic individuals having attributes that are conducive to research excellence. With a focus on geosciences, we use the experiences of an autistic $\mathrm{PhD}$ student to evaluate why academia can be inaccessible, and propose simple strategies that can reduce and remove barriers to academic success. We suggest that minor changes to communication, the academic environment and better disability awareness can make significant differences to the inclusion of disabled researchers, particularly those with autism. These changes would also benefit the wider scientific community and promote research and teaching excellence.
\end{abstract}

\section{Introduction}

"Strength lies in differences, not in similarities" (Covey, 2013). Strength in academic research and teaching lies in equality, diversity and inclusion - of different perspectives, ideas, disciplines, life experiences and personal attributes. Diversity within scientific research teams improves the quality of science (Nature, 2014) and increases paper citations (Adams, 2013; Freeman and Huang, 2014), as well as promoting institutional flexibility, adaptability and acceptance (Powell, 2018). But the current diversity of researchers within academia is unrepresentative of the wider population (e.g. Bernard and Cooperdock, 2018). Disabled people in particular are excluded (HESA, 2019a, d), and many people with disabilities feel that academia is a hostile, ableist environment, within which non-stereotypical ways of working are unaccepted and not tolerated (Brown et al., 2018; Fleming, 2019). There is a pervasive negative stigma associated with disability, and the fear of negative repercussions on an academic career prevents researchers, particularly those in the earlier stages of their careers, disclosing disabilities (Guardian, 2017; NCSES, 2019c).

Autism is a disability that is particularly under-represented within higher education. Members of the general public are fifty times more likely than an academic to disclose an autism diagnosis (Russell et al., 2014; HESA, 2019a); a difference that is likely to be due to both under-representation and under-disclosure of autism within academia. Yet autism does not affect intelligence (Lai et al., 2014), and many autistic individuals have traits that are conducive to great success within academia (e.g. Ioan, 2003; Baron-Cohen et al., 2007; Anderson et al., 2017). Unfortunately, academia currently presents many barriers that hinder the success of individuals with autism.

Here we review the under-representation of disabled students and staff within geosciences and higher education more generally, and the impact that this under-representation has on research. Using the perspectives and experiences of the first author, an autistic PhD student, we consider autism within academia: the barriers that are encountered on the journey to academic success and simple strategies to reduce or remove these. We stress that every individual, regardless of disability, encounters unique barriers within academia and has unique strategies to overcome these that may differ from those suggested here. Given our personal experiences within geosciences, we focus on the challenges that this discipline presents, including the need for travel, field work and working with a range of people in a wide range of environments. However, many of the barriers that we discuss are relevant 
across disciplines. We extend previous studies that focused on undergraduate experiences (reviewed by Anderson et al., 2017), and describe how strategies that improve the accessibility of events, conferences and fieldwork (discussed by Brown et al., 2018; Fleming, 2019; Houghton and Gordon, 2019) can be applied more widely across academia to benefit autistic individuals. Raising awareness of the barriers faced by disabled researchers, and taking action to remove these, is vital to improve researcher diversity. Until researcher diversity improves, the diversity of research, and the diversity of solutions to critical research problems will be unnecessarily restricted.

\section{Disability within higher education}

\subsection{Disabled researchers}

People with disabilities are under-represented throughout higher education, and the geosciences sector is no exception. In the UK, approximately $19 \%$ of the working-age population are disabled (DWP, 2018), yet only $14 \%$ of undergraduates, $11 \%$ of postgraduate research students, and $4 \%$ of academics disclose a disability (HESA, 2019a, d). The proportion of individuals within academia that disclose a disability has increased over time, but the difference between the number of students and academic staff that disclose a disability has increased annually (Fig. 1b). Within geosciences, disability disclosure amongst postgraduate research students is approximately half that for undergraduate students (Fig. 1c, HESA, 2019b). These data therefore suggest that postgraduate research is less accessible to disabled students and/or postgraduate students avoid disclosing their disability. For academic staff, disability disclosure rates within the United States increase with seniority (Fig. 2). An increase in disability rates with age can be expected (e.g. DWP, 2019), but the number of early-career researchers who disclosed a disability is disproportionately small. This is likely to be due to underreporting of disability, in addition to under-representation of disabled individuals within academia (NCSES, 2019c). Thus the negative stigma, and fear of negative repercussions, make it preferable for both students and staff to avoid disclosing a disability, despite the protection provided by the Equality Act (2010) (UCU, 2012; Brown and Leigh, 2018). Effort is required to ensure that higher education is an environment which is inclusive, equal and equitable, and within which the negative stigma associated with disability is removed.

\subsection{Research output}

Diversity is a critical component of success across sectors and across disciplines (Forbes, 2011). Companies who consciously employed disabled people have reported a competitive advantage, with increased employee reliability, punctuality, productivity and retention (Lindsay et al., 2018). Within academia, researcher diversity increases the diversity of solutions to research problems, and improves the quality of the research (measured by paper numbers and paper citations, Nature, 2014). Research papers in a range of fields, including geosciences, have $5 \%-10 \%$ more citations when the research team is ethnically diverse (Freeman and Huang, 2014). Surprising discoveries are made when the same data are interpreted by people with different disabilities, and therefore different perspectives, and working within a diverse team encourages researchers to become more flexible, adaptable and accepting (Powell, 2018). Thus the underrepresentation of disabled researchers, many of whom could offer unconventional perspectives on research problems, may restrict the quality and quantity of research. Geosciences could particularly benefit from better diversity of researchers, given the breadth of scientific research being undertaken, and consequently the breadth of solutions that are required for research problems within the sector.

\section{Autism in higher education}

\subsection{The autism spectrum}

Every person on the autism spectrum is different. Each has a unique experience of the world, and a unique combination of strengths and difficulties. Many autistic people are diligent, determined and resilient, good at solving problems, studying things in great detail and thinking about things in novel ways (e.g. Ioan, 2003; Baron-Cohen et al., 2007; Best et al., 2015; Anderson et al., 2017, 2018). These skills can be conducive to academic excellence - the theory of relativity, the basis of classical mechanics and the first measurement of Earth's density were all derived by scientists thought to have been autistic (Ioan, 2003). When autistic individuals have been included within research groups, productivity has increased (Powell, 2018). However, the cognitive differences of those with autism are not always considered within academia, making some academic environments inaccessible (Fig. 1, Madriaga, 2010; Lai et al., 2014). By improving understanding of the barriers academia creates, and the ways in which these can be reduced or removed, it is hoped that the representation of autistic researchers within academia will increase, which will benefit research.

\subsection{Reducing and removing barriers}

\subsubsection{Raising awareness}

Individuals of all ages are less inclined to interact with their autistic peers (Sasson et al., 2017). Consequently, a significant proportion of people with autism (including university students) feel rejected, isolated and lonely (Anderson et al., 2017). This contributes to mental health difficulties, which are co-morbid in around $80 \%$ of autistic adults (Gelbar et al., 2014; Anderson et al., 2017; Cage et al., 2018). As a researcher, peer-rejection restricts opportunities to net- 

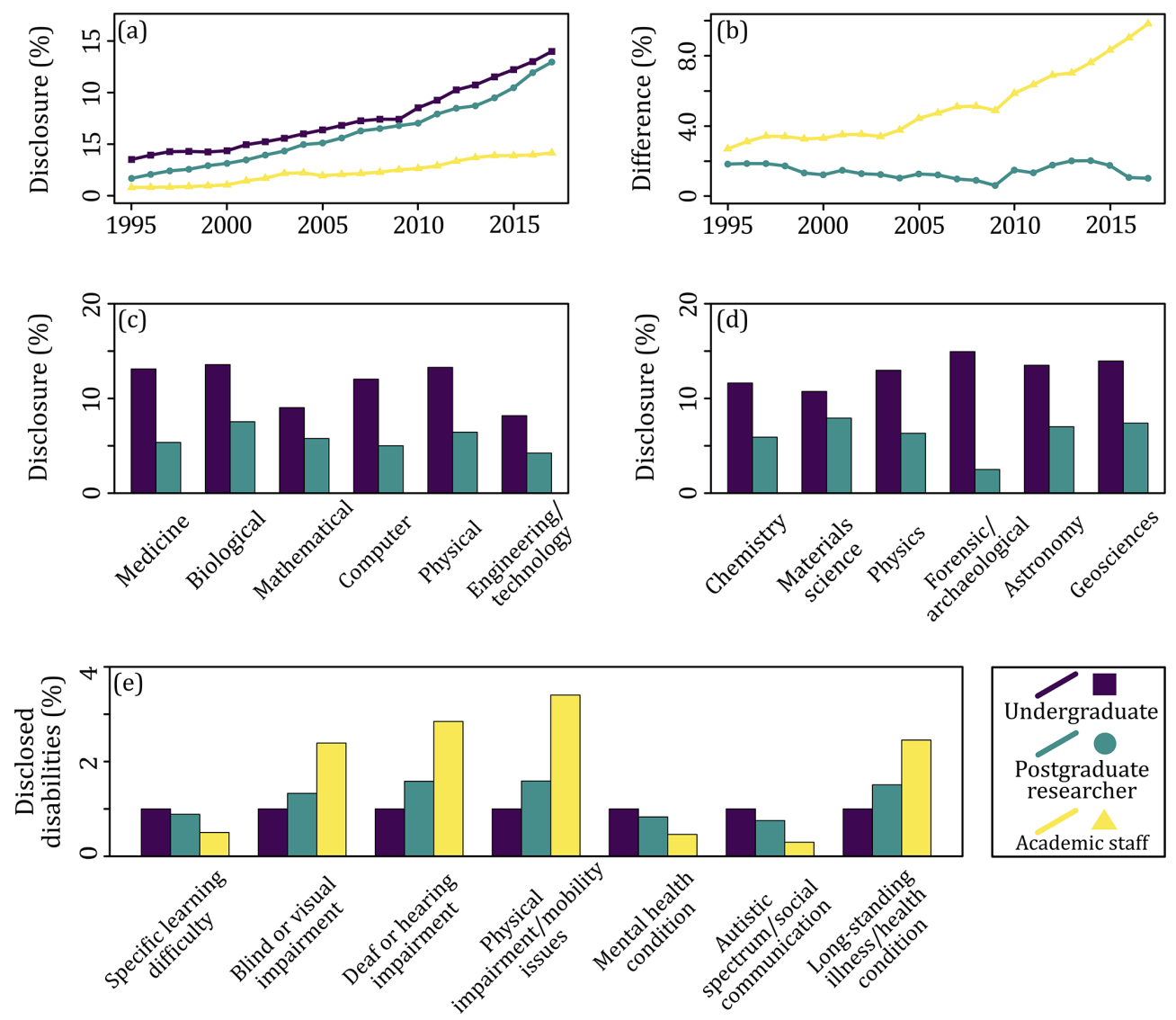

Figure 1. Disability disclosure within higher education. (a) The percentage of individuals who disclosed a disability increased between 1995 and 2017. (b) The difference in the percentage of undergraduate and postgraduate students who disclosed a disability remained relatively constant since 1995, with around $1.5 \%$ more undergraduates disclosing a disability compared to postgraduates. However, the difference in the percentage of undergraduate students and academic staff who disclose a disability has increased almost every year; a much greater proportion of undergraduate students report a disability compared to academic staff. Students who complete their undergraduate science (c) or physical science (d) studies are approximately twice as likely as postgraduate students to disclose a disability, although there is discrepancy between disciplines. Disclosure rates are averaged for four academic years, 2014-2015 to 2017-2018. (e) The type of disclosed disability varies between groups, with autistic spectrum conditions being particularly underrepresented within postgraduate research students and academic staff. Data are averages between 2014-2015 and 2017-2018, and results are normalized against undergraduate results. Data from HESA (2019a, d).

work and discuss and improve research, as well as hindering well-being within what is widely considered a demanding environment (e.g. Toews and Yazedjian, 2007). Within geosciences, an individual who is rejected by their peers is likely to find some aspects of fieldwork impossible. For example, geological mapping is often unsafe to complete without a field buddy, and conducting a geophysical survey may be impossible without colleagues. Thus, an autistic individual within geosciences may be more limited by research techniques than their peers, and autistic students may also have a more limited range of undergraduate project options.

An understanding of autism promotes inclusion of neurodiverse colleagues (Nevill and White, 2011), and academic staff who have had disability training have more positive attitudes towards disabled students (Murray et al., 2009). Awareness of autism makes the workplace less stressful and more conducive to productivity (Cage et al., 2018). Autism awareness also makes autistic individuals more comfortable to disclose their disability, and students who disclose their autism have more positive university experiences (Anderson et al., 2018).

Disability training, which includes and promotes accessibility for students with "invisible" disabilities such as autism, is compulsory for sports clubs and societies at some institutes, but is lacking elsewhere within higher education, particularly for undergraduate students (Matthews, 2009). The difficulties that autistic people experience typically cannot be seen, so colleagues cannot make simple inclusive adjustments (analogous to adopting a slower pace when walking with someone with mobility difficulties) unless autism awareness is improved. 


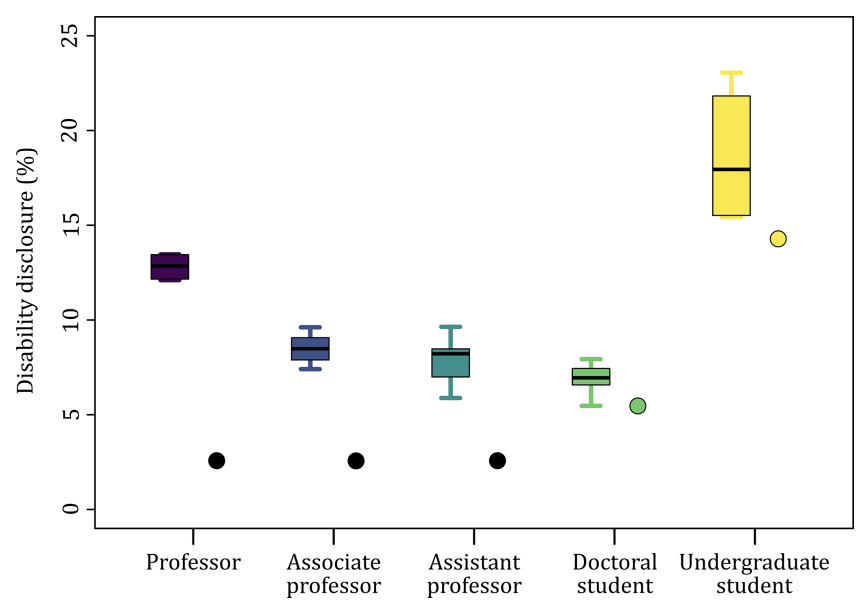

Figure 2. Disability disclosure for physical scientists by seniority. Boxplots show disability disclosure rates for seven disciplines within physical sciences for universities and colleges within the United States. United States data from NCSES (2019a) (proportion of students who enrolled in 2016 and disclosed a disability), NCSES (2019b) (proportion of individuals who received a doctoral degree in 2017) and NCSES (2019c) (proportion of academic staff who were employed in universities and 4-year colleges in 2017 and disclosed a disability). Circles show the most equivalent UK data, presented as averages for physical sciences (undergraduate and doctoral students, data from HESA, 2019b), or mathematical, biological and physical sciences (data from HESA, 2019c). We do not distinguish between disability disclosure rates for academic staff with different seniority within the UK. Some differences in disclosure rates between countries are attributed to differences in data collection. Undergraduate students (the proportion of students enrolling in 2016 who disclose any disability) are the most likely to disclose a disability. For the United States, disclosure rates then increase with seniority from doctoral students through to professor, whereas for the UK disability disclosure rates for academic staff are significantly lower than for students.

\subsubsection{Effective communication}

A core feature of autism is difficulty with social interactions and social communication (APA, 2013). This can make it difficult to interpret what others mean, particularly when irony, figures of speech and idioms are used (Attwood, 2015). It can seem like everyone is speaking a different language, which takes time to tune in to and understand. It may take longer for an autistic individual to formulate an answer and respond to a question, particularly in unfamiliar environments (e.g. Knott and Taylor, 2014), and in group situations when there are multiple people to engage with (Madriaga and Goodley, 2010). Thus, communicating with colleagues whilst working in an unfamiliar field location can be particularly challenging for autistic individuals. Research opportunities often develop from holding discussions with a range of colleagues, giving seminars, conference talks and presenting posters not purely from writing research papers, which an autistic individual may find easy in comparison. So for researchers who find verbal communication a challenge, academic success, and developing support networks to enhance success, can seem beyond an insurmountable barrier.

Effective communication benefits everyone, particularly those with communication difficulties. Minor changes to verbal communication can make a major difference to an autistic individual's ability to engage and collaborate with peers, and develop academic and social networks. For example:

1. Taking pauses, particularly before and after asking questions to allow information to be absorbed and processed, and an answer formulated.

2. Addressing people directly to remove ambiguity about who is being spoken to. This is particularly important when non-verbal communication might be misunderstood.

3. Using literal language to avoid confusion or misunderstanding.

4. Offering to rephrase or clarify what has been said.

5. Allocating a chairperson, or group leader, who facilitates the inclusion of everyone within a conversation, and who ensures collective understanding by summarizing discussions recapping key points.

Some individuals may use other forms of communication, for example writing or typing questions, thoughts or comments, using a notetaker or speech-to-text technology or communicating through a familiar person. The preference for communication style may change depending on the situation; in the field, inclement weather may make some forms of communication impossible. Yet, despite their communication difficulties, most autistic people do not seek constant solitude. Many strive to improve their communication skills, benefit greatly from participating in group events (particularly those which are structured), and appreciate the benefits that communicating and interacting with others brings (e.g. Van Hees et al., 2015). If relatively minor adjustments can be made that facilitate better communication between autistic individuals and their colleagues, academia could become a far less daunting, and far more accessible environment for autistic researchers.

\subsubsection{Environment adjustments}

Around $95 \%$ of autistic individuals have sensory differences (Leekam et al., 2007; Crane et al., 2009). The impacts of sensory sensitivities on everyday functioning are often significant, but typically underestimated (Knott and Taylor, 2014). The most common sensory difference is hyper-sensitivity to noise (Attwood, 2015); every sound and every voice can seem loud and intense, and background noises can be impossible to ignore (Madriaga, 2010; Knott and Taylor, 2014). Other sensory input - light (particularly from florescent lighting), smell, touch and taste can also be distracting, if not 
painful (Attwood, 2015). The more sensory input there is, the harder it is to process information, and too much sensory input can become overwhelming, making it impossible to process anything - described as sensory overload.

A great allure of geosciences is working in some of the world's most fascinating environments - access to many of these involves long-distance travel and negotiating sensoryintensive travel hubs. Geoscience students and academics might also be expected to work in a range of offices and laboratories, often alongside numerous other researchers. Academics and research students engage with talks in lecture theaters and seminar rooms around the world, simultaneously blocking out distractions from lighting, buzzing laptops, and people seated in close proximity. They tend to hold discussions at busy conference dinners, within crowded poster halls, and at spontaneously-organized social events. These environments are often inaccessible to an autistic individual, thereby hindering academic opportunities and success.

The increasing consideration of sensory sensitivity amongst conference and event organizers is welcomed. For example, extending poster and PICO session lengths at the European Geosciences Union General Assembly has reduced overcrowding (Buiter, 2018) and a special interest group on accessible computing has published an Accessible Conference Guide (Trewin et al., 2019). Access to additional rooms, reducing overcrowding, allowing for discussions outside of the busiest areas and providing a quiet area to unwind can be welcome additions to events for all attendees (Brown et al., 2018). Clear signage at events can help with navigating unfamiliar, sensory-intensive environments. If attending some, or all of an event is impossible, web-streaming of talks, online question-and-answer sessions (perhaps through Twitter, e.g. Brown et al., 2018), and online training can provide accessible solutions. When aspects of fieldwork, or getting to a field site, are challenging, technologies have successfully been used to improve accessibility (Houghton and Gordon, 2019). Examples of useful technologies include tablets, virtual reality, aerial photography, and tour guide or live feed systems. Ever-developing technology, alongside increasing awareness of sensory sensitivity, should reduce barriers to academic success.

\subsubsection{Routine and structure}

Autistic individuals perceive the world differently and many rely on structure, routine, and sameness in order to succeed within often-chaotic and non-logical environments (Attwood, 2015). Making the spontaneous decisions required to work flexibly can be time-consuming for individuals who need to weigh up multiple pros and cons before proceeding with anything. Even when structure can be established within the normal working environment, time away from the office requires new routines, and can be unpredictable. Fieldwork can require a particularly flexible, adaptable, approach. Preparation and forewarning can help autistic individuals de- viate from sameness and predictability in order to make the most of academic opportunities.

Given adequate time, Google Earth, street imagery, and photographs of building interiors can be used to increase familiarity with a new environment or field site. Schedules or agendas, even if they are approximate, provide a structure to days in the field, training sessions and meetings. This reduces uncertainty and decreases anxiety, making it easier for autistic individuals to engage and contribute - and this benefits everyone. Thus, with preparation and understanding, functioning within unfamiliar environments - including those which are sensory-intensive - can become less intimidating and pose less of a barrier to the academic success of autistic individuals.

\section{Conclusions}

The geosciences are a fascinating, rewarding and challenging field, but the diversity of research does not yet align with the diversity of researchers within the sector, including those with disabilities. The negative stigmatization of disability within academia is detrimental to recruitment and retention of disabled researchers, and reduces rates of disability disclosure, particularly for early-career researchers. Autism is significantly under-represented within academia, even though many autistic researchers have attributes which are conducive to research excellence. Thus the barriers that academia presents to the inclusion and success of autistic researchers must be addressed. Adjustments that do not require significant time or expense, such as improving autism awareness and acceptance, making adjustments to the academic environment, and considering the effectiveness of verbal communication can significantly reduce the barriers that autistic individuals encounter within higher education. These adjustments can also improve the quality and quantity of research, the productivity of a research group and the flexibility and adaptability of other academics. The geosciences are a fascinating field, with ever-increasing global importance, and access to this should be shared with as many people as possible.

Data availability. Research data are from a third party, available from HESA (2019a, b, c, d) and NCSES (2019a, b, c).

Author contributions. The study was conceived and designed by NCT with support from JHJ. The manuscript was written by NCT with contributions from JHJ. JHJ provided supervision for the project.

Competing interests. The authors declare that they have no conflict of interest. 
Special issue statement. This article is part of the special issue "Diversity and equality in the geosciences (EGU2019 EOS6.1 \& US4, AGU2018 ED41B, JpGU2019 U-02)". It is not related to a conference.

Acknowledgements. We thank Fiona Knott and an anonymous reviewer for their thorough and constructive reviews, and the Topical Editor Jill Karsten for their helpful comments that have greatly improved the manuscript. We thank Richard Herd for his helpful and insightful discussions, and Jade Eyles and Bridie Davies for support throughout the project.

Financial support. This research has been supported by the Natural Environment Research Council through the EnvEast Doctoral Training Partnership (grant no. NE/L002582/1).

Review statement. This paper was edited by Jill Karsten and reviewed by Fiona Knott and one anonymous referee.

\section{References}

Adams, J.: The fourth age of research, Nature, 497, 557-560, https://doi.org/10.1038/497557a, 2013.

Anderson, A. H., Stephenson, J., and Carter, M.: A systematic literature review of the experiences and supports of students with autism spectrum disorder in postsecondary education, Res. Autism Spect. Dis., 39, 33-53, https://doi.org/10.1016/j.rasd.2017.04.002, 2017.

Anderson, A. H., Carter, M., and Stephenson, J.: Perspectives of university students with autism spectrum disorder, J. Autism Dev. Disord., 48, 651-665, https://doi.org/10.1007/s10803-0173257-3, 2018.

APA: Diagnostic and statistical manual of mental disorders: DSM5, Vol. 5, American Psychiatric Association, 2013.

Attwood, T.: The complete guide to Asperger's syndrome, Vol. 2, Jessica Kingsley Publishers, 2015.

Baron-Cohen, S., Wheelwright, S., Burtenshaw, A., and Hobson, E.: Mathematical talent is linked to autism, Human Nat., 18, 125131, https://doi.org/10.1007/s12110-007-9014-0, 2007.

Bernard, R. E. and Cooperdock, E. H. G.: No progress on diversity in 40 years, Nat. Geosci., 11, 292-295, https://doi.org/10.1038/s41561-018-0116-6, 2018.

Best, C., Arora, S., Porter, F., and Doherty, M.: The relationship between subthreshold autistic traits, ambiguous figure perception and divergent thinking, J. Autism Dev. Disord., 45, 4064-4073, https://doi.org/10.1007/s10803-015-2518-2, 2015.

Brown, N. and Leigh, J.: Ableism in academia: where are the disabled and ill academics?, Disabil. Soc., 33, 985-989, https://doi.org/10.1080/09687599.2018.1455627, 2018.

Brown, N., Thompson, P., and Leigh, J. S.: Making academia more accessible, Journal of Perspectives in Applied Academic Practice, 6, 82-90, https://doi.org/10.14297/jpaap.v6i2.348, 2018.

Buiter, S.: More time for all presentation types in the new EGU General Assembly schedule, availble at: https://www.egu.eu/news/446/ (last access: 30 October 2019), 2018.

Cage, E., Di Monaco, J., and Newell, V.: Experiences of autism acceptance and mental health in autistic adults, J. Autism Dev. Disord., 48, 473-484, https://doi.org/10.1007/s10803-017-33427, 2018.

Covey, S. R.: The 7 habits of highly effective people: powerful lessons in personal change, 25th Edn., Simon and Schuster, London, UK, 2013.

Crane, L., Goddard, L., and Pring, L.: Sensory processing in adults with autism spectrum disorders, Autism, 13, 215-228, https://doi.org/10.1177/1362361309103794, 2009.

DWP: Disability data tables, Family Resources Survey: financial year 2016/17, Table 5, https://www.gov.uk/government/statistics/ (last access: 19 October 2019), 2018.

DWP: Disability data tables, Family Resources Survey: finanical year 2017/18, Table 4.1, https://www.gov.uk/government/statistics/ (last access: 15 March 2020), type: dataset, 2019.

Fleming, N.: How to organize a conference that;s open to everyone, Nature, 571, S46-S47, https://doi.org/10.1038/d41586-01902253-9, 2019.

Forbes: Global diversity and inclusion: fostering innovation through a diverse workforce, Tech. Rep., Forbes Insights, New York, 20 pp., 2011.

Freeman, R. B. and Huang, W.: Strength in diversity, Nature, 513, p. 305,2014

Gelbar, N. W., Smith, I., and Reichow, B.: Systematic review of articles describing experience and supports of individuals with autism enrolled in college and university programs, J. Autism Dev. Disord., 44, 2593-2601, https://doi.org/10.1007/s10803014-2135-5, 2014.

Guardian: If I tell my university about my disability, will I be seen as a weak link?, The Guardian, https://www.theguardian.com/higher-education-network/ (last access: 30 October 2019), 2017.

HESA: HE academic staff by disability and employment function 2014/15 to 2017/18, HE Staff Data, Table 5, https://www. hesa.ac.uk/data-and-analysis/staff/table-5 (last access: 19 October 2019), 2019a.

HESA: HE qualifiers by subject area, principal subject, level of qualification obtained, mode of study, disability marker and academic year, HE Student Data, Table 33, https: //www.hesa.ac.uk/data-and-analysis/students/table-33 (last access: 14 March 2020), 2019 b.

HESA: HE full-time academic staff by cost centre and contract salary 2016/17, HE Staff Data, Table 16, https://www.hesa.ac. uk/data-and-analysis/staff/table- 16 (last access: 15 March 2020), 2019c.

HESA: UK domiciled student enrolments by disability and sex 2014/15 to 2017/18, HE Student Data, p. Table 15, https: //www.hesa.ac.uk/data-and-analysis/students/table-15 (last access: 16 October 2019), 2019d.

Houghton, J. and Gordon, C.: Access Anglesey: An inclusive and accessible field course, Teaching Earth Sciences, 44, 7-11, 2019.

Ioan, J.: Singular scientists, J. Roy. Soc. Med., 96, 36-39, 2003.

Knott, F. and Taylor, A.: Life at university with Asperger syndrome: a comparison of student and staff 
perspectives, Int. J. Inclusive Educ., 18, 411-426, https://doi.org/10.1080/13603116.2013.781236, 2014.

Lai, M.-C., Lombardo, M. V., and Baron-Cohen, S.: Autism, The Lancet, 383, 896-910, https://doi.org/10.1016/S01406736(13)61539-1, 2014.

Leekam, S. R., Nieto, C., Libby, S. J., Wing, L., and Gould, J.: Describing the sensory abnormalities of children and adults with autism, J. Autism Dev.1 Disord., 37, 894-910, https://doi.org/10.1007/s10803-006-0218-7, 2007.

Lindsay, S., Cagliostro, E., Albarico, M., Mortaji, N., and Karon, L.: A systematic review of the benefits of hiring people with disabilities, J. Occup. Rehabil., 28, 634-655, https://doi.org/10.1007/s10926-018-9756-z, 2018.

Madriaga, M.: I avoid pubs and the student union like the plague: students with Asperger syndrome and their negotiation of university spaces, Child. Geogr., 8, 39-50, https://doi.org/10.1080/14733280903500166, 2010.

Madriaga, M. and Goodley, D.: Moving beyond the minimum: socially just pedagogies and Asperger's syndrome in UK higher education, Int. J. Inclusive Educ., 14, 115-131, https://doi.org/10.1080/13603110802504168, 2010.

Matthews, N.: Teaching the "invisible" disabled students in the classroom: disclosure, inclusion and the social model of disability, Teach. High. Educ., 14, 229-239, https://doi.org/10.1080/13562510902898809, 2009.

Murray, C., Lombardi, A., Wren, C. T., and Keys, C.: Associations between prior disability-focused training and disability-related attitudes and perceptions among university faculty, Learn. Disability Q., 32, 87-100, https://doi.org/10.2307/27740359, 2009.

Nature: Diversity challenge, Nature, 513, p. 279, https://doi.org/10.1038/513279a, 2014.

NCSES: Doctorate recipients, by field and disability status: 2017, Women, Minorities, and Persons with Disabilities in Science and Engineering, Tables 7-6, https://ncses.nsf.gov/pubs/nsf19304/ data (last access: 30 October 2019), 2019a.

NCSES: Major field of undergraduates, by disability status: 2016, Women, Minorities, and Persons with Disabilities in Science and Engineering, Tables 2-7, https://ncses.nsf.gov/pubs/nsf19304/ data (last access: 30 October 2019), 2019b.
NCSES: Science, engineering, and health doctorate holders employed in universities and 4-year colleges, by occupation, disability status and faculty rank: 2017, Women, Minorities, and Persons with Disabilities in Science and Engineering, Tables 928, https://ncses.nsf.gov/pubs/nsf19304/data (last access: 30 October 2019), 2019c.

Nevill, R. E. A. and White, S. W.: College students' openness toward autism spectrum disorders: improving peer acceptance, J. Autism Dev. Disord., 41, 1619-1628, https://doi.org/10.1007/s10803-011-1189-x, 2011.

Powell, K.: These labs are remarkably diverse - here's why they're winning at science, Nature, 558, 19-22, https://doi.org/10.1038/d41586-018-05316-5, 2018.

Russell, G., Rodgers, L. R., Ukoumunne, O. C., and Ford, T.: Prevalence of parent-reported ASD and ADHD in the UK: findings from the millennium cohort study, J. Autism Dev. Disord., 44, 31-40, https://doi.org/10.1007/s10803-013-1849-0, 2014.

Sasson, N. J., Faso, D. J., Nugent, J., Lovell, S., Kennedy, D. P., and Grossman, R. B.: Neurotypical peers are less willing to interact with those with autism based on thin slice judgments, Sci. Rep., 7, 40700, https://doi.org/10.1038/srep40700, 2017.

Toews, M. L. and Yazedjian, A.: The three-ring circus of academia: how to become the ringmaster, Innov. High. Educ., 32, 113-122, https://doi.org/10.1007/s10755-007-9046-8, 2007.

Trewin, S., Hanson, V., Rode, J., Mankoff, J., Morrs, M. R., Fitzpatrick, D., and Hwang, F.: ACCESS accessible conference guide, http://www.sigaccess.org/welcome-to-sigaccess/ resources/accessible-conference-guide/ (last access: 18 November 2019), 2019.

UCU: Disclosing a disability, Tech. Rep., London, UK, University and College Union, London, 2012.

Van Hees, V., Moyson, T., and Roeyers, H.: Higher education experiences of students with autism spectrum disorder: challenges, benefits and support needs, J. Autism Dev. Disord., 45, 16731688, https://doi.org/10.1007/s10803-014-2324-2, 2015. 